\title{
El poeta Jacint Verdaguer a l'Arcàdia romana
}

\author{
Jaume MEDINA \\ Universitat Autònoma de Barcelona \\ jaume.medina@uab.cat
}

\begin{abstract}
RESUM
El poeta català Jacint Verdaguer compongué obres de caire bucòlic durant la seva joventut i descriví la Plana de Vic d'acord amb les característiques del locus amoenus i de l'Arcàdia virgiliana. En el present article és estudiada la història del seu ingrés a l'acadèmia poètica de l'Arcadia Romana, de la mà del seu amic Jaume Collell, també poeta.
\end{abstract}

Paraules clau: l'Arcadia Romana, Locus amoenus, poesia catalana, tradició clàssica, Jacint Verdaguer, Jaume Collell

[Recibido, junio 2012; aprobado, diciembre 2012]

\section{Catalan poet Jacint Verdaguer at the Roman Arcadia academy}

\begin{abstract}
The Catalan poet Jacint Verdaguer composed bucolic works during his youth, and described the Vic Plain according to the characteristics of the locus amoenus and the Arcadia, as described by Roman poet Virgil. In this paper we are going to study the history of his admission to the Roman Arcadia, thanks to his friend and poet Jaume Collel.

Keywords: Roman Arcadia, locus amoenus, Catalan poetry, Classical tradition, Jacint Verdaguer, Jaume Collell
\end{abstract}


Fa uns quants anys que vaig publicar un estudi titulat de primer L'Arcàdia verdagueria$n a^{l}$ i després, en una versió ampliada, L'Arcàdia del poeta Jacint Verdaguer, ${ }^{2}$ en el qual examinava la part inicial de la Crida de les festes de Sant Miquel dels Sants, fill predilecte i patró de la ciutat de Vic, escrita pel poeta de Folgueroles l'any 1866, quan tenia només vint-i-un anys, uns temps en què es dedicava a fer composicions de caire bucòlic.

Un any després de l'aparició d'aquest poema verdaguerià, és dir, el 1867, va tenir lloc la primera esbartada, nom amb què van ser conegudes les reunions dels poetes de l'Esbart de Vic, unes trobades que s'havien d'anar celebrant a partir de llavors gràcies a l'impuls del Círcol Literari de la ciutat, a la Font del Desmai, prop de la Torre de Morgadès (una masia del terme de Folgueroles), en la qual van participar els joves clergues Jaume Collell i Jacint Verdaguer (que cantà missa a Sant Jordi de Puigseslloses, a poca distància de la Font del Desmai, el 1870). En aquella primera sessió, Jacint Verdaguer llegí un text en què parlava de la "nostra plana, lo cistell de flors, lo bressolet d'or penjat entre cel i terra, en què plagué a Déu posar-nos a tots per ésser-hi bressats per mans d'àngels..."

Verdaguer va viure molt a la vora de la Font del Desmai, tant en els temps de la seva infantesa a Folgueroles, com en els de la seva joventut passats a can Tona, mentre estudiava per capellà. El lloc, si ens el mirem amb els ulls de Marian Picó, en la pintura realitzada el 1870 (que podem contemplar al Museu Episcopal de Vic), era certament ben bucòlic: el poètic desmai i la densa vegetació que envolta el poeta, en donen cabal testimoni. Per ser una autèntica Arcàdia, hi falten només els espaiosos herbeis, el rierol juganer i els tendres vedells pasturant.

Com se sap, l'Arcàdia és una regió de Grècia, situada al cor del Peloponnès, que va esdevenir ja durant l'antiguitat, sobretot gràcies a Virgili, el lloc ideal per excel·lència, el paradís freqüentat per uns pastors que més aviat eren poetes, la contrada del benestar i de la felicitat. ${ }^{3}$ Des de llavors, els escriptors que han volgut descriure un paisatge ideal han tingut com a suprema referència les èglogues virgilianes, en què restava plasmada d'una manera definitiva l'ambientació d'aquesta Arcàdia ideal.

És per això que alguns poetes italians de quatre segles enrere, en voler crear una institució que vetllés per la dignitat de la poesia, van pensar en l'Arcàdia virgiliana. En el seu Viatge a Itàlia (una obra que tan bellament va traduir al català l'enyorat Rafael Bofill), Goethe ${ }^{4}$ exposa les raons per les quals va ser creada l'acadèmia romana de l'Arcàdia. Deia:

Sembla que durant el segle dissetè la poesia italiana va anar empitjorant per diversos conceptes: cap al final de la centúria alguns homes cultes i sensats hi criticaven l'absoluta descurança del contingut, aleshores denominat bellesa interna, però també de la forma, la bellesa externa, per tal com a través de barbarismes, versos intolerablement durs, figures i trops mancats, i, sobretot, contínues i desmesurades hipèrboles, metoní-

\footnotetext{
${ }^{1}$ Aparegut a "Serra d'Or", febrer de 2002, pàgs. 28-30.

2 Publicat a "Revista Internacional d'Humanitats" (Barcelona-São Paulo), Ano X, N. 1, 2007, pàgs. 5-12. http://www.hottopos.com

${ }^{3}$ Sobre el descobriment de l'Arcàdia i la seva caracterització com a pàtria ideal dels poetes per part de Virgili, vegeu: Bruno Snell, Las fuentes del pensamiento europeo. Estudios sobre el descubrimiento de los valores espirituales de occidente en la antigua Grecia. Madrid (Editorial Razón y Fe, S. A.) 1965, pàgs. 395-426.

${ }^{4}$ J. W. Goethe, Viatge a Itàlia. Traducció i notes de Rafael M. Bofill. Pròleg de J. Muñoz Millanes. Barcelona (Columna) 1996, pàgs. 511-515.
} 
mies i metàfores, se n'havien marcit la gràcia i la dolçor formals que hom es complau a trobar-hi.

Els adeptes d'aquestes vies errònies, en canvi, rebentaven, com sol esdevenir-se, la bellesa pura i excel-lent, per tal de seguir veient respectats llurs abusos, i això no podia seguir essent tolerat per homes intel-ligents i formats. El 1690, finalment, un grup de persones conscients i capacitades resolgué emprendre un altre camí.

A fi d'evitar, però, que les seves reunions no cridessin l'atenció i donessin lloc a reaccions contràries, s'aplegaren a l'aire lliure, en les rodalies abundants en jardins com els nombrosos que la mateixa Roma enclou en el recinte dels seus murs. Això els comportava endemés un avantatge: tenien més a prop la natura, i, a cel obert, podien percebre millor l'esperit dels primers temps de l'art poètica. Allí, en llocs més o menys ocasionals, s'acomodaven sobre l'herbei o s'asseien damunt de restes i blocs de pedra d'antigues arquitectures, on un simple coixí ben flonjo bastava per a honorar qualsevol cardenal que pogués trobar-s'hi present. Hom discutia sobre conviccions, fonaments, projectes, i es llegien poemes on s'intentava ressuscitar l'esperit de la poesia més antiga i de la selecta escola toscana. Algú, en certa ocasió, degué cridar, entusiasmat: «Vet aquí la nostra Arcàdia!» I així aparegueren el nom de la societat i el seu caràcter idíl-lic. No es pretenia la protecció de cap personatge de pes i d'influència, i hom no volia cap prepòsit ni president. Un custodi obria i tancava els espais arcàdics en els casos de necessitat, li donava suport un consell elegit entre els membres més vells.

El mateix Goethe explica com procedia l'acadèmia poètica romana per escollir els seus membres. Deia:

Quan vaig arribar a Roma aquesta societat acabava de complir cent anys, i, malgrat diversos canvis de lloc i de tendències, havia mantingut sempre una dignitat exterior, bé que no pas un gran prestigi; si algun foraster més o menys significatiu sojornava a Roma, no es deixava quasi mai d'aprofitar l'ocasió per a incorporar-l'hi, tant més que el guardià d'aquesta poètica hisenda podia anar mantenint així uns moderats ingressos.

Val a dir que el poeta de torn, en ingressar a l'acadèmia romana i esdevenir "pastor arcadi de nombre", adoptava un nom extret de la mitologia grega. Goethe, per exemple, va dur el de Megalio.

Finalment el poeta alemany, després d'haver-se resistit repetidament a acceptar la invitació a formar part de l'acadèmia poètica, va ser rebut en aquesta institució el dia 4 de gener de 1787. Així és com ell mateix explica l'estira i arronsa amb els pretendents:

Ja a les darreries de l'any anterior vaig veure'm assetjat per una invitació que també em sembla haver estat una conseqüència d'aquell inoportú concert pel qual havíem posat al descobert ben irreflexivament el nostre incògnit. Potser caldria admetre així mateix altres motius a causa dels quals pogués haver-hi diversos interessats en el meu ingrés a l'«Arcàdia» en qualitat d'il-lustre pastor. Jo m'hi resistia una i altra voltes, però finalment vaig haver de cedir als amics, que ho consideraven quelcom molt significatiu.

Siguin o no sincers els mots de Goethe, el que és cert és que l'autor del Viatge a Itàlia va sentir-se molt honorat de formar part de la cèlebre institució. Una mostra ben clara és que només entrar en el llibre on explica totes aquestes coses, hom hi troba l'epígraf Et in Arcadia ego, amb què ressalta en particular un dels molts episodis remarcables de la seva visita al país meridional. 
Per estrany que pugui semblar, això mateix és el que va ocórrer al poeta vigatà Jaume Collell, durant la seva estada a Roma l'any $1883 .{ }^{5}$ De finals de maig d'aquell any és una carta no datada ${ }^{6}$ que li adreçà mossèn Jacint Verdaguer i que deia:

\section{Estimat Jaume:}

Vetaquí la poesía de Montserrat y eix article de "La Veu" reproduit en Italia, que m acaba d enviar per tu 1 inolvidable Andreu Balaguer, invitante á tu y á mi, (creyent que estarias alguns dias assi) per oir missas, dissapte, en sufragi de 1 ánima de sa mare.

En est moment es á casa mestre Mariano, mirant la professó del Pi, que passa per sota 1 balcó de casa. Ell volía darte son llibre de Cavaylería de Ramon Llull.

Teu in Corde Jesu.

Jacinto Verdaguer, Pbre.

¿Qué tinch de respondre als Arcades y en quina llengua? ${ }^{7}$

Aquest document epistolar havia estat recollit per primera vegada a Carteig històric. Correspondència epistolar de Mossen Jacinto Verdaguer a Mossen Jaume Collell qui la publica ab un prólech $i$ anotacions. Vic (Gazeta de Vich) 1929, pàgs. 152-153. El canonge Collell anotava la carta dient:

\footnotetext{
${ }^{5}$ Hom pot seguir detalladament l'evolució del viatge del canonge a Roma, per les notícies que es troben a l'obra: Jaume Collell, Efemerides dels meus 50 anys de sacerdoci. Seguides de El reyet del Taga (novela postuma). Portic de J. Gros Raguer. Vic (Gazeta de Vich) 1938, pàgs. 52-54:
}

"[Any 1882]

$[\ldots]$

LO DIA 14 DE DESEMBRE - Surto de Vich per anar a Roma una temporada per assistir a les Conferencies de la Academia de Sant Tomàs, fundada per S.S. Lleó XIII, y al mateix temps cumplir una missió especial sobre les questions y dissidencies dels catòlichs espanyols.

Me vaig hospedar en una residencia de Pa- $\|$ [pàg. 53] res Dominicans francesos (Via della Panneteria) hont vaig estar sempre ben atès y ben acompanyat. Gràcies a Déu no tinguí novedat en la salut en los cinch mesos llarchs que durà la meva estada en la Ciutat Eterna.

De les meves impressions n'enviava unes Cartes Romanes en mon periòdich $\mathrm{La}$ Veu del Montserrat, que després les he publicades en un volum titolat Roma, il·lustrat per lo pintor famós Enrich Serra.

Pel Mes de Maig fiu una sortida a Nàpols, podent assistir al miracle de la liqüefacció de la sanch de Sant Genaro.

ANY 1883

MARS, 22 (DiJOUS SANT) - Avuy he tingut lo consol de rebre la comunió en la Missa celebrada per Sa Santedat Lleó XIII en son Oratori.

MARS, 23 (DIVENDRES SANT) - Avuy a dos quarts de set de la vesprada he sigut rebut en audiencia particular, molt íntima, per Sa Santedat. Hi ha la següent nota marginal: «Confirma hoc Deus quod operatus es in nobis»".

LOS DIAS 6, 7, 8 Y 9 DE MAIG los passí a Nàpols, visitant, Pompeya, y assistint a la benedicció del primer temple de Nostra Senyora del Roser, que després ha vingut a ser una basílica molt concorreguda y celebrada.

|| [pàg. 54]

EL DIA 10 a Montecassino, estudiant en lo Arxiu del famós Monastir benedictí, los documents per probar que en lo sigle XV vingueren monjos de allí a Montserrat. Hi demoraren poch temps.

DIA 21 DE MAIG - Marxo de Roma, y arribo a Barcelona lo dia 23 al vespre. Dia 30 arribo a Vich".

${ }^{6}$ Vegeu: Epistolari de Jacint Verdaguer. Volum IV (1883-1885). Transcripció i notes per Josep Maria de Casacuberta i Joan Torrent i Fàbregas. Barcelona (Editorial Barcino) 1974, pàg. 48, document núm. 347. [D'ara endavant, el citaré com Epistolari]. A diferència del canonge Collell, que posava a la carta la data de juny de 1883, els editors de l'Epistolari verdaguerià dataven la carta a Barcelona, 31 de maig de 1883, i anotaven: “Aquesta carta, que Collell data amb el mes i l'any, degué ésser escrita el mateix dia de la carta 346; data concordant amb la referència del segon apartat relativa a la processó de la parròquia del Pi, la qual se celebrà el dijous, 31 de maig”. La carta 346 era datada a Barcelona, 31 de maig de 1883; vegeu: Epistolari, pàg. 47.

${ }^{7}$ Dins: Epistolari, pàg. 48, document núm. 347. 
En la meva estada a Roma del any 1883, alguns amichs me volgueren fer l'obsequi de presentarme com candidat a una antigua y prestigiosa Academia que ostentava el nom clássich de Arcadia Romana. Precisament en l'any 1879 havía pogut assistir a una solenne straordinaria adunanza che gli Arcadi la sera di sabato, 22 Febbraio 1879... Per fare atto di ossequio alla Santitá di nostro Signore Papa Leone XIII gloriosamente regnante.

Només que Jaume Collell ho va acabar acceptant tan sols després d'haver obtingut el beneplàcit a una condició per ell posada: que també rebés aquest nomenament el seu amic Jacint Verdaguer. Deia:

Quan, doncs, me proposaren ésser membre de la Arcadia, vaig dir al qui n'era Custode Generale Monsenyor Stefano Ciccolini, Prefecte de la Biblioteca Vaticana, que havía de ser a condició de que fos anomenat igualment Mossen Jacinto Verdaguer.

\section{I després contava encara:}

Aixís fou acceptat, y se'ns lliurá el corresponent títol o diploma, donant a Verdaguer el sobrenom arcádich de Ermadoro Coronídeo y a míl de Artamene Dardanio. Per aixó en eixa carta preguntava l'amich quina resposta havía de donar als Arcades, institució que nosaltres jóvens sense tenirne noticia, l'any 1867, havíam imitat en les sentades del Esbart a la Font del Desmay, aixís com l'Arcadia Romana tenía son domicili social al Bosco Parrasio.

La premsa vigatana havia donat notícia de l'esdeveniment en els mateixos moments en què ocorria. Així, el setmanari "La Veu del Montserrat", que dirigia el canonge Collell, deia, a la secció Dietari del Principat del seu número del 24 de febrer de 1883 (pàg. 62):

-Tenim la particular satisfacció de poder comunicar á nostres lectors que han sigut nombrats acadèmichs de la ARCADIA de Roma, nostre Director lo Sr. canonge Collell, lo Rnt. Mossen Jacinto Verdaguer, y'l reputadíssim pintor D. Enrich Serra. Com es costum, en lo títol de nombrament se ha donat á quiscun dels nous arcades lo sobrenom poètich, que son respectivament los de Artamene Dardanio (Collell), Ermadoro Coronideo (Verdaguer) y Glaucildo Enopeo (Serra).

En la Biblioteca del Serbatoio de la Arcadia la primera obra catalana que hi ha pres lloch, es lo poema la Atlántida. ${ }^{8}$

\footnotetext{
${ }^{8}$ Actualment té el número de referència 4.i.23 al Fondo dell'Arcadia Romana, que es troba situat a la Biblioteca Angelica de Roma. Es tracta d'un exemplar de l'edició: La Atlántida, Poema de Mossen Jascinto Verdaguer que obtingué'l premi de la Excma. Diputació Provincial de Barcelona en los Jochs Florals de 1877 ab la traducció castellana per Melcior de Palau. Estampat a despeses del Excm. Sr. D. A. Lopez. (A sota, hi ha un segell imprès amb la llegenda SEPARANDO JUNXIT). Barcelona, Estampa de Jaume Jepús, MDCCCLXXVIII. Al colofó s'hi diu que ha estat imprès el dia 24 de juliol, vigília de sant Jaume. A la portadella, on figura simplement el títol de l'obra, hi ha, a la part de dalt, un escrit a mà (la lletra, però, no és pas la de Verdaguer) i en tinta negra, que diu: Ex dono auctoris (Ermadoro Coronideo); a la part de sota del títol, hi ha un tampó, que diu: Biblioteca degli Arcadi. Vaig poder tenir a la mà aquest exemplar intons el dia 7 de desembre de 2011, a l'impressionant i espectacular Salone Vanvitelliano del segle XVIII, dins de l'esmentada Biblioteca Angelica. L'exemplar no té cap dedicatòria de Verdaguer, perquè el poeta va lliurar el llibre al
} 
Com es pot veure per la data de publicació del número de "La Veu del Montserrat", el nomenament havia tingut lloc pel febrer de 1883. Jacint Verdaguer en donà les gràcies a Jaume Collell en una carta datada a la Badia de Cadis, el 9 de març de 1883. ${ }^{9}$ Deia:

En ma ultima ${ }^{10} \mathrm{~m}$ oblidí de darte las gracias per haverme fet academich de la famosa Arcadia. Com no he rebut cap document, no he donat tampoc las gracias al president ó director. M'agrada molt, especialment per tu y per l'Enrich Serra, pintor ab qui simpatisarás molt.

Com podem veure, Verdaguer confessa no haver escrit cap carta a Roma per donar les gràcies pel nomenament. Els editors de l'Epistolari diuen en una nota a la carta 347 que "probablement mossèn Collell, en tornar de Roma, portà a Verdaguer el diploma d'acadèmic de l'Arcàdia Romana". "És segurament per això que en la carta de 31 de maig Verdaguer pregunta a Collell: "Qué tinch de respondre als Arcades y en quina llengua?"12 Finalment, en una carta de Verdaguer a Collell datada a Barcelona, 7 a 12 octubre de 1883, el primer diu: “¿Donares tu las gracias per mi del nombrament de arcade, ab que m'honraren ab tan bona companyia?" 13 I els editors conclouen, en una nota: "Es veu que mossèn Collell donà les gràcies en nom propi $\mathrm{i}$ en els de Verdaguer $\mathrm{i}$ Enric Serra". ${ }^{4}$

D'altra banda, els editors de l'Epistolari anotaven la referència verdagueriana a l'Arcàdia, al·ludint, en primer lloc, a la notícia donada per "La Veu del Montserrat", que acabem de reproduir. Després feien referència a la nota que el canonge Collell posà com a aclariment a la carta de Verdaguer de finals de maig de 1883 (reproduïda més amunt). Després, encara, donaven notícia de tres articles titulats De l'Arcadia Romana, que el canonge Collell publicà a la "Gazeta de Vich" els dies 23, 25 i 28 d'octubre de $1924 .{ }^{15}$ I acabaven dient: "No hem trobat, entre els nombrosos documents verdaguerians de la Biblioteca de Catalunya, el títol corresponent a Verdaguer; tampoc el de Collell no apareix en la relació de títols i diplomes conservats pel canonge publicada per A. Pérez de Olaguer (El canónigo Collell, 394 ss.); cf. Dulcis amicitia, 148”.

Per la nostra banda, vam fer també consultes a la Biblioteca de Catalunya, a l'Arxiu Històric de la Ciutat de Barcelona i al Museu Verdaguer de Vil·la Joana de Vallvidrera, i vam arribar a la mateixa conclusió que els editors de l'Epistolari verdaguerià. Cal tenir present també que els papers del canonge Collell van ser cremats a Vic pels revolucionaris del $1936 .^{16}$

\footnotetext{
canonge abans de saber la destinació que aquest li donaria. Tanmateix, al catàleg del Fons de l'Arcàdia, no hi figura cap obra de Jaume Collell.

${ }^{9}$ Vegeu: Epistolari, pàgs. 32-36. El fragment reproduït es troba a la pàg. 33.

${ }^{10}$ La carta anterior de Verdaguer a Collell és datada a Barcelona, 3 de març de 1883. Vegeu: Epistolari, pàg. 31.

${ }^{11}$ Vegeu: Epistolari, pàg. 49, nota 7.

${ }^{12}$ Vegeu: Epistolari, pàg. 48.

${ }^{13}$ Vegeu: Epistolari, pàg. 93.

${ }^{14}$ Vegeu: Epistolari, pàg. 94.

${ }^{15}$ Vegeu l'Apèndix d'aquest article, on transcrivim sencers aquests articles de Jaume Collell.

${ }^{16}$ No és impossible, però, que algun dia aparegui el diploma, ja que la biblioteca del canonge va ser venuda a un llibreter de vell.
} 
Tanmateix, per una consulta als arxius de l'Arcadia Romana, hem pogut saber que els noms dels dos poetes vigatans figuren als registres de l'entitat. En efecte, la doctora Giovanna Rak, que està al front de la secretaria de l'Arcàdia i a la qual donem d'aquí estant les més efusives gràcies, ens feia saber que les eleccions d'aquells consten a la pàgina 110r del registre "Arcadi della Custodia Ciccolini" (Stefano Ciccolini va ser "Custode Generale" de l'Arcàdia des del 1870 fins al 1888). Aquesta pàgina 110r té a la capçalera la indicació de l'any: “1883 - dell'Arcadia 193 - Olimp. 48 a.3”.

Jaume Collell hi és registrat amb el número 847 :

\section{7 - 30 gennaio}

Giacomo Collell, Sacerdote, Canonico della Chiesa Cattedrale di Vich / col nome di Artamene Dardanio /

a proposta di Eristeno Nassio - Mr [= Monsignore] Agostino Bartolini / Amildo Pelleneo - Mr Luigi Tripepi

Jacint Verdaguer hi tenia el número 850:

" 850 - 4 febbraio

Giacinto Verdaguer, di Vich (Spagna), Maestro in Gaya Ciencia / col nome di Ermadoro Coronideo /

a proposta di Artamene Dardanio - D. Giacomo Collell /

Glaucildo Enopeo - D. Enrico Serra

Una consulta posterior de la mateixa doctora Rak als arxius de l'Arcadia Romana va deixar al descobert que no hi havia ni composicions poètiques ni tampoc documents epistolars de cap dels dos autors. Per tant, hem de concloure que Jacint Verdaguer, a pesar d'haver tingut una primera intenció d'agrair el nomenament, no va arribar a enviar cap carta a l'Acadèmia. I que Jaume Collell, si va donar les gràcies per aquests nomenaments, ho va fer de viva veu.

Tal com es pot veure per la nota de Jaume Collell a la carta de Jacint Verdaguer, el canonge vigatà es relacionava molt bé amb monsenyor Stefano Ciccolini, prefecte de la Biblioteca Vaticana i Custode Generale de l'Arcàdia, encara que tanmateix entrés a formar part de l'acadèmia a proposta de dos altres monsenyors. En canvi, Jacint Verdaguer hi entrà gràcies als bons oficis del seu amic Jaume Collell (que l'havia precedit en l'ingrés) i d'Enric Serra i Auqué (Barcelona 1859 - Roma 1918), pintor resident a la capital italiana des del 1878, al qual Lleó XIII encarregà una marededéu que, reproduïda en mosaic, va ser regalada pel papa al monestir de Ripoll l'any 1891.

És així com aquests dos poetes catalans entraren en el panorama poètic internacional, formant part des de ben joves d'una institució amb gran renom no tan sols entre els poetes, sinó també entre els artistes d'altres camps, sobretot el de la música i el de la pintura. Tanmateix, és una vertadera llàstima que no ens hagi arribat per cap dels dos costats el diploma acreditatiu de l'entrada de Verdaguer i de Collell a l'acadèmia poètica del Gianicolo. 


\section{APÈNDIX}

Jaume Collell, De la Arcadia Romana. “Gazeta de Vich”, 23 d'octubre de 1924.

I

No fa gayre temps que en alguns diaris de Barcelona se dava compte de que havía sigut nomenat membre de la antiga societat literaria que porta'l títol pastoril de Arcadia, un indivíduo del Capítol de aquella Seu. Y al darli la enhorabona per aytal distinció, s'hi afegía que era'l primer catalá que havia entrat en aquell gremi de gent lletrada.

Y aixó no es pas veritat; y avuy volem rectificar la especie, no per pruhija infantil de vanagloria, sino per posar les coses en son lloch, y fer constar públicament que'l dia 30 de Janer del any 1883, foren expedits en el Bosco Parrasio, que aixís se titula la Sede de la Arcadia Romana, els títols honorífichs de Arcades a Mossen Jacinto Verdaguer y a Mossen Jaume Collell, otorgant al primer el nom arcádich de Ermadoro Coronídeo, y al segon el de Artamene Dardanio.

A quasi tots mos lectors aqueixa nomenclatura els fará un efecte estrany, com d'una societat secreta. Res d'aixó.

El segell del títol de Arcade no pot ser més inofensiu y trempat: es la famosa flauta de Pan, dels antichs pastors grechs y romans, voltada del simbólich llorer; y'l document ve autorisat ab la firma pastoril del Custode Generale, Agesandro Tesporide, que no era altre que mon insigne amich, Monsenyor Stefano Ciccolini, canonge de la Basílica Vaticana y Prefecte de la Biblioteca pontifícia.

Jo, com Mossen Cinto, no n'havíam pas fet fressa de aquesta distinció, y tots dos havíam donat les gracies a qui pertocava, desant el document arcádich sense que'l públich se'n enterás de que'ls dos capellans Mestres en Gay Saber de Catalunya, formassen també part de la noble Arcadia Romana.

Mes ara que se'ns ha presentat ocasió, creyém que no será pas enutjós als nostres habituals lectors que'ls ne fasse una explicació, al cap de quaranta anys de guardar, ben recaptadet ab altres documents, lo simpátich títol de Arcade Romá.

Aqueixa Societat literaria i artística de la Ciutat dels Papas es de antiga e ilustre nissaga, y data de aquella florida época dels humanistas del Renaixement, del qual foren mestres y caps de brot, ilustres purpurats y prelats meritíssims. Y com en la ciutat de Roma hi havía un moviment literari que perpetuava la bona tradició dels clássichs heretada y per la Iglesia fomentada, se formá aqueixa, diguemli confraría, de la Arcadia, que tenía les seves reunions o sentades en algun de aquells llochs encantats dels suburbis romans, en alguna de aquelles ville de les quals ne queda encara algun exemplar que dona alta idea de lo que foren aquelles cases principesques de la Ciutat Eterna.

Los fundadors de la Arcadia Romana me'ls figuro molt semblants als prohoms barcelonins, que en el sigle XVIII fundaren la Academia dels Desconfiats, de la qual després ne sortí la actual Academia de Bones Lletres, que pot ostentar un honrosíssim historial, y que, á mon entendre, ara té una missió trascendental per Catalunya, com és, salvar la Lléngua de les mans que han vingut a deformarla, fins al punt de convertirla en un llenguatge amorfo, embutit de exotismes y neologismes, sense cap fonament racional. JAUME COLLELL, Pbre.

Jaume Collell, De la Arcadia Romana. “Gazeta de Vich”, 25 d'octubre de 1924. 
La primera vegada que vegí funcionar a la famosa Academia dels Arcades fou en l'any 1879, ab ocasió de la Romería dels periodistas católichs de tot lo mon, en homenatge al Papa Lleó XIII qui feya un any que en son front venerable cenyía la Tiara pontifícia.

A un periodista romá, distingit ecclesiástich qui més tart fou elevat a la dignitat Cardenalicia, Monsenyor Tripepi, director de la revista Il Papato y redactor del Osservatore Romano, se li acudí la idea de que, al celebrar lo aniversari primer de la elevació al Papat de Joaquim Pecci, los escriptors católichs de tot l'univers fossen representats a Roma y fessen homenatge de adhesió y de amor filial al Papa que, ja en son adveniment se presentava com un renovador de la vida católica: Lumen in Caelo.

Passaren de mil los adherits, y entre ells hi figurava la Redacció de LA VEU DEL MONTSERRAT, Setmanari popular de Catalunya, baix la direcció del qui subscriu aquestes ratlles. A Roma aní en companyia del editor D. Ramon Anglada, y de les impressions de aquella Romería se'n feu després un opúscol. A mes de la meva representació en aquella magna Assamblea n'hi portava d'altres de revistes religioses de Catalunya, y a la vegada hi duya una colecta feta en lo nostre Setmanari per lo Diner de Sant Pere, lo primer volum de LA VEU DEL MONTSERRAT luxosament enquadernat, y un exemplar de La Atlántida que era una joya. A més de la enquadernació en pell de Russia ab ornamentació apropiada hi havía una portada de vitela ab miniatures pintades per D. Mariano de Picó, una dedicatoria firmada per Mossen Verdaguer y un distich llatí compost pel P. Fita de la Companyía de Jesús. Tot açó jo ho vaig oferir al Papa.

Entre'ls diversos actes a que doná lloch aquesta Romería de periodistas, hi hagué una Vetllada literaria-musical, organisada per la Arcadia. Encara'n guardo'l programa que ab son color de fulla seca, quan me'l miro, la imaginació d'un vol se me'n va a la inmensa Sala hont se desgraná un devassall de poesía y de cant. Era alló verament una solemnitat more romano. No diré res de la concurrencia atapahida, honrada ab la presencia de cardenals y alts dignataris que s'asseyen en cadires de repós al centre de la sala. De senyores soprani y contralti, totes de gala y representants algunes de nobles families, n'hi havia unes 20 , y de tenori y basci (homens) eran una trentena. No dich res del programa musical que feya caure la baba als aficionats.

De la part literaria vos diré que'ls Arcades se volgueren lluhir, començant per un prólech llatí del Custode, Monsenyor Ciccolini, y arreu arreu vingueren poesíes en 13 lléngues, essent els lectors tot gent granada en representació de les Tretze nacións que per ordre alfabétich venían anotades desde la Armena fins a la dels Ungheresi, que tingueren dos lectors. Per l'Espanya parlá el canonge Silvestre Rongier que era'l Rector de la iglesia nacional de Montserrat.

En resum una festassa d'aquelles que son un regal per l'esperit que s'envola en les serenes regions de l'art. Allí poguerem sentir la intensa palpitació dels cors, oferint lo solemne adunanza, tribut de la vella Arcadia Romana al qui en sos Estatuts anomena Pastor Supremus.

En lo vinent article veurem com entraren a formarne part els dos capellans, Mestres en Gay Saber pel Consistori dels Jochs Florals de Barcelona.

$$
\text { JAUME COLlell, Pbre. }
$$


Jaume Collell, De la Arcadia Romana. “Gazeta de Vich”, 28 d'octubre de 1924.

\section{III}

La meva llarga estada a Roma, l'any 1883, la considero com un dels beneficis majors que $m$ 'ha otorgat a plenes mans la divina Providencia. La paraula romanisarse tanca molts sentits i desperta molts sentiments. Per un eclesiástich, romanisarse vol dir tant com sentit més intensament alló que, en els transports de la seva santa agonía, repetía Santa Teresa de Jesús: en fin, Señor, soy hija de la Iglesia. Per qui s'ha ficat un xich endins de la historia, romanisarse es entendre millor l'acció providencial que guia a la humanitat, pensament generador de la gran obra de Bossuet; y no diguem res de lo que significa romanisarse per qui sent l'art i sobre tot l'arqueología.

Donchs tot aixó, ab una permanencia de mesos en la Ciutat Eterna, arriba a penetrar y remintolar com un bàlsam en totes les potencies del ánima, fins a participarne la pobre envoltura corpórea. Si a tot aixó hi agreguém la ditxa de haver pogut en la litúrgica matinada del Dijous Sant del 1883 ohir la missa y rebre la Comunió de mans de Lleó XIII, y l'endemá, a la misteriosa vesprada del Divendres, esser rebut en audiencia, més que privada, íntima d'una intimitat verament paternal, per aquell home extraordinari qui feu rendir a un Bismarck y senyalá en ses Encícliques rublertes de doctrina les certeres orientacions pera l'acció católica en els temps moderns, podrá compendre'l lector d'eixos articles, si tinch rahó de senyalar ab pedra blanca la meva estada a Roma en l'any 1883 .

Aqueixa estada, com coincidía ab la maror que a Espanya, y sobre tot a Catalunya, tenía conturbades les conciencies ab les may prou plorades divisions dels católichs, fou diversa y malignament interpretada. Sobre tot aquells caritatius que viuen de la murmuració cotidiana, feyan corre la especie de que ademés de portarhi a Roma una missió confidencial, hi anava a intrigarhi per una mitra. Infeliços! Per aqueixa feyna no m'hauría hagut de moure de casa, y ho dic aixó sense ombra de jactancia, perqué podría facilment estampar aquí algunes cartes probatories.

A Roma hi vaig fer lo que m'havía proposat, y una mica més. Vaig evitar que's parlés de otorgarme certes distincions per un sacerdot ben honroses; y aquest títol de que estem parlant, de membre de la literaria Arcadia Romana, no sols me vingué sense ni remotament demanarlo, sino que quan vaig saber de qué's tractava, diguí resoltament que jo no acceptaría'l títol, sino s'otorgava igualment a Mossen Jacinto Verdaguer.

Y veus aquí com els dos Mestres en Gay Saber foren admesos en la antiga societat romana de la Arcadia, l'un ab el sobrenom de Ermadoro Coronideo, y l'altre, servidor de vostés, ab l'apelatiu de Artamene Dardanio. De lo qual no n'hauria parlat, si al cap de quaranta anys de esser Arcade, no hagués vingut, ara fa poch, qui asseverás que era'l primer catalá honrat ab lo diploma pastoril y poétich.

Aqueix diploma, redactat en italiá clássich, termina ab la següent clàusula que'm sembla hem cumplert ab tota fidelitat, tant Mossen Cinto com jo mateix:

«L'Arcadia nel dichiara[r]vi aggiunto al suo Comune confida que non solo manterrete la osservanza delle sue leggi, ma darete opera eziandio [sic] perché sempre piú fiorisca con la dignitá delle lettere l'onore dell'arcadico istituto».

Y sota la data del 30 de Janer de 1883, porta'l document la signatura del Custode Generale, Agesandro Tesporide, qui era'l canonge de la Basílica Vaticana, Monsenyor Esteve Ciccolini, qui m'honrá ab la seva amistat, franquejantme l'estudi de alguns manuscrits catalans de la Biblioteca Vaticana.

JAUME COLLELL, Pbre. 